Between June 24 and 27 we were cruising in the packice from $74^{\circ}$ to $76^{\circ} 5^{\prime}$ lat., where we sighted Conical Rock. It was, however, impossible to penetrate towards Cape York, but only to the north-west. As we saw a fjord north-east of Conical Rock, which was, however, not marked on the chart, we steered into it and cast anchor. Seeing some human beings on the shore, we landed, and found them to be a couple of Esquimaux families, rude and uncivilised, but obliging. They only stay here in the summer for catching the rotges which breed here in large numbers, while during the winter they sojourn on an island in Wolstenholme Sound, where they hunt the walrus. They possessed, however, no boats. We purchased some of their tools, \&c., clothes of birds' skin, and some bear and fox hides.

On July 27 we sent two Esquimaux to examine the ice towards Cape York, who came back and reported that it was still lying along the south-east coast. For four days we attempted to penetrate northwards, running the ship in every direction where we saw a lead, but, as we everywhere encountered the ice barrier and were several times in great danger of being crushed, we "stood about," and arrived at Upernivik on the night of August I.

It appears thus that the last severe winter in Greenland has also extended up Smith's Sound, as an example of which I may mention that Nares, who on the same day as we, in 1875 , steamed up Smith's Sound towards Cape York, found the sea entirely free from ice.

That the chief object of this part of the expedition, while in my command, should not have been realised, I extremely regret; but I console myself with the fact that every effort in human power was done in order to carry it out.

I may say, however, that the exceedingly rich, zoological, botanical, and hydrographical fruits of the expedition towards Cape York and back, fully repay the cost and labour of the voyage. We leave here (August 2) for the Waigat, where I intend continuing my geological researches, while the rest of the expedition on board start on a four day's zoological and hydrographic excursion towards America. When that is over we start for Egedesminde, to take Nordenskjöld on board.

Dr. Berlin, who accompanied Nordenskjöld on his journey on the ice in Greenlaud, writes as follows :-

On July 3 the march began from the Auleitsivik Fjord. The party consisted of Nordenskjöld, myself, Sergeant Kjellström, the second mate Herr Johannesen, two hunters, Sevalsen and Kræmmer, two sailors, and the Lapps, Anders and Lars. We reached on sleighs, according to solar observations, eighty miles (English) inland, reckoned from the ice border, when the Lapps were sent forward 130 miles further, a distance fixed by their own judgment, which may be fully relied on. This was done because the deep, loose snow prevented us proceeding on sleighs, while it was eminently suitable for the "skidor," or snow "runners" (they are not "shoes") of the Lapps. We found no "ice-free" country, in fact the latter may, by this expedition, be fully proved not to exist, neither in this nor in any other latitude in Greenland. By the above-mentioned calculation, and estimating the shore-line at seventy miles inland, we have succeeded in reaching 280 miles into Greenland, which is more than balf its width, while the Lapps, from their point of return, saw the land a good distance further east. The ice rose at the furthest spot reached to 7000 feet above the sea, and was still seen to rise to the east. The journey lasted a month.

\section{THE PRESENT CONDITICN OF FISH CULTURE}

WITHIN the past few years the science of fish culture has made rapid progress, and radical changes have been made both in the apparatus and methods em- ployed. Experience has enabled the fish-culturists to improve upon the old forms of hatching-boxes and troughs, while the propagation of additional species has necessitated the invention of new forms. The International Fisheries Exhibition, now in progress in London, has brought together valuable collections from the leading specialists of all parts of the world. A study of these enables one to form a very correct idea of the present condition of the science.

The subject is now sufficiently understood to warrant a division of the hatching apparatus into four classes: (I) apparatus for heavy eggs ; (2) for semi-buoyant eggs ; (3) for floating eggs; (4) for adhesive eggs.

Heavy eggs like those of the salmon and trout are hatched with little difficulty. An almost endless variety of apparatus intended for eggs of this class is exhibited, but it may all be referred to one of three divisions depending upon the direction of the current of water, namely, that with a horizontal current, that with an upward current, and that with a downward current. Apparatus of the kind first mentioned is most commonly employed, but that with an upward current has many points of superiority. Chief among these are economy of space, saving of water, and the prevention of injurious sedimentary deposits. In the United States, where, owing to the enormous quantity of eggs handled, economy of space is a necessity, the upward current is quite generally employed. A number of the American forms are provided with from ten to fifteen wire trays; these, when filled with eggs, are placed one above another, so that the entire volume of water must pass through each of them on its way through the compartment.

Semi-buoyant eggs, like those of the shad (Alosa sapidissima) and whitefish (Coregonus clupeiformis) require a treatment entirely different from those already mentioned, as their specific gravity is but slightly greater than that of fresh water, and they are easily carried about by the currents. The best results are obtained by directing an upward current against the eggs, thus producing a gentle but constant motion, and keeping them partiaily or wholly suspended in the water. As little attention is now given to hatching semi-buoyant eggs outside of the United States and Canada, the collections of these countries contain nearly everything of interest in this class. We find here various forms of floating boxes adapted to river currents, apparatus fed by water which is introduced under pressure through closed pipes, and mechanical apparatus requiring motive power. The firstnamed is admissible where the work is limited or where rigid economy is a necessity. The second is preferable in any city where hydrant water can be obtained or when the work is sufficiently extensive to warrant the use of a pumping-engine. The third is occasionally employed where large quantities of eggs are hatched, but it is more expensive than the one last named, and the results are usually less satisfactory. Apparatus of the second kind is ordinarily made of glass, its efficiency depending largely upon the motion imparted to the eggs and the position of the outflow through which the waste water and dead eggs escape. This opening in nearly all of the apparatus exhibited is placed at the top of the jar, and a current strong enough to carry off all of the dead eggs frequently carries many of the good ones with it, while the motion of those that remain is often so violent as to cause serious injury. An improvement in apparatus of this class has recently been made by Marshall McDonald of Washington, D.C. His apparatus consists of a closed jar having an outflow through a glass tube which passes into the interior of the jar, and can be raised or lowered at will. With this apparatus the dead eggs are easily removed by the slightest currents, and excellent results are obtained.

More difficulty is experienced in finding suitable apparatus for floating eggs, like those of the cod (Gadus morrhua), than for any other class. Only five forms intended for floating eggs are exhibited. None of these 
are entirely satisfactory, but two of them are used with moderate results. The first is a rectangular wooden box with a wire-cloth bottom, and lateral openings even with the water-line covered with the same material. Around the outside of the box, just below the openings, is a strip of wood four inches wide which rests upon the surface of the water and serves as a float to keep it in position. This float forms an inclined plane leading to the lateral openings, and the waves striking against it run up the slight incline passing through the wire covering into the interior of the box, thus giving a constant circulation from above, the surplus water passing out through the bottom. The other form consists of an ordinary hatching trough divided into compartments by means of transverse partitions. The trough is placed at a slight incline, and the water passes from one compartment to another through a shallow tin spout placed in a notch at the top centre of the partition. In these compartments are smaller wooden boxes with wire-cloth bottoms. These are so placed in the compartments that their forward ends shall rest under the spouts that conduct the waste water from the compartment above, the free ends being thrown slightly upward by their own buoyancy. With a box thus placed in a compartment filled with water, the stream that is kept constantly running falls into its deepest part, creating a circular current, the waste water passing out through the bottom and up around the sides on its way to the next compartment, the wire-cloth preventing the escape of the eggs.

Much of the apparatus for adhesive eggs, like those of the herring (Clupea harengus), is very primitive, consisting simply of boxes lined with pine and spruce boughs or twigs, in which the parent fish are kept during the spawning period, the eggs adhering to the pine boughs. In some, the pine boughs are fastened to movable frames to admit of their transportation to other waters, but in most they are stationary, the fry being intended for the waters in which they are hatched. A decided improvement on the above are the more modern forms intended for artificially impregnated eggs. Unquestionably the best apparatus exhibited is a wooden trough with plates of glass placed at right angles to its length, invented by Frank N. Clark, of Northville, Michigan. The eggs are taken and impregnated upon these glass plates, and at once spread evenly over the surface by means of a feather. They soon adhere to the plates, which are then placed in grooves which have been cut into the side of the trough, three-fourths of an inch from each other. The grooves are so cut that every alternate glass shall rest on the bottom of the trough, with the others half an inch above, so that the water shall pass over the top of the first, beneath the lower edge of the second, over the third, \&c., on its way through the trough, thus supplying a constant current to the eggs. Other apparatus made of muslin is exhibited, but this, for several reasons, chief among which is the tendency of the cloth to retain any sedimentary matter that may be in the water, is less effective.

Formerly the material of which hatching apparatus was composed was a matter of much importance to the fishculturist; but the introduction of asphalt varnish has rendered the choice of materials a secondary consideration: the fish-culturist has now to consider the adaptability and cost of materials only, for almost any substance, whether metal or wood, if properly coated with asphalt, can be successfully employed.

Illustrations of recent methods of securing and retaining the adult fish until the eggs have been secured, are exhibited. At one of the hatching stations in Canada the fish taken along the shores are transported to saltwater ponds, where they are kept until the eggs and milt have fully developed. A decided advantage is claimed in salt over fresh water, as in it there is a much smaller percentage of loss among the fish, the presence of fungus (Saprolegnia ferax), that dreaded foe of all fish-cultural operations, being entirely unknown. In the McCloud River, California, a dam is placed across the stream directly opposite the hatchery, and the fish, finding further progress impossible, drop back into the deeper portions of the channel, a few rods below, where they can be easily caught by the aid of a haul-seine. In Grand Lake Stream, Maine, nets are stretched across the mouth of the river to direet the fish into basins of netting, where they are retained till the spawning season arrives.

In localities where the supply of eggs is obtained from the ripe fish taken in the nets of the fishermen, the United States Fish Commission some time since introduced steam launches for visiting the fishing grounds and distributing the spawn-takers among the more important fishing stations, and again bringing them with their take of eggs to the hatchery. This plan worked well, and enabled the Commission to obtain a much larger number of eggs than formerly, with little or no increase in expense. In 1882 the plan of stationing professional spawn-tal ers at the larger fishing shores, to remain during the height of the spawning season, was adopted. These are expected to examine every fish landed, and to secure all ripe eggs, which, after impregnation, are placed upon wire trays covered with damp cloths, and set in a cool place to await the arrival of the steam launch, which usually makes daily trips to collect the eggs and carry them to the hatchery. In the absence of the launch the eggs are often shipped by the ordinary river steamers.

The improvements in hatching apparatus, with a view to economy of space were important steps in the progress of fish culture, as the introduction of new forms greatly increased the capacity of the hatcheries in which such apparatus was employed. But even with these improvements fish-cuiturists have often found it difficult to handle as many eggs as they desired, owing to the limited duration of the spawning period. Their hatcheries were crowded for a short time, and the simultaneous hatching of the eggs required a large force of messengers to distribute the fry. As the spawning season had usually passed by the time the first fish were hatched, no more eggs could be secured, and the hatchery had to be closed till the following year. This difficulty is now practically overcome in several ways. It is found by Sir James Maitland that the spawning season for fish kept in artificial ponds is considerably affected by food. An abundance of hearty food at the time when the ovaries are beginning to enlarge hastens their development, while a scanty supply of coarse food considerably retards their growth. By judicious feeding one can arrange to have the fish of different ponds spawn at different dates, so that two crops instead of one can be produced at bis hatchery. Refrigerators are now successfully employed in cases of wild fish, when the spawning time cannot be controlled by food. The surplus eggs, after the hatchery has been filled, are placed on cloth trays and corded up in the refrigerator until such time as there is room for them in the hatchery. They should be examined at intervals, and if in poor condition should be washed in ice water and again returned to the trays. Trout ova three, five, and seven months old respectively were exhibited in the German department, the eggs being apparently in excellent condition. The use of refrigerators, however, is at present limited to winter.spawning fishes. With summer-spawners it has thus far resulted disastrously.

Those interested in the acclimatisation of fishes have much to stimulate and encourage them. From all quarters come encouraging reports of the successful introduction of fishes into new waters. The shad of the Atlantic coast of America (Alosa sapidissima) is now taken in such quantities in the rivers of California as to claim a place among the food fishes of the Pacific. The California trout (Salmo irideus) is now grown in the waters of Australia, Japan, and Germany: with the fish-culturists 
of the last-named country it is a special favourite. The German carp (Cyprinus carpio) has, through the efforts or Prof. Baird, been scattered broadcast over the United States, an 1 in the warmer regions grows with surprising rapidity, attaining a weight more than double that of fish of the same age in their native waters. Eggs of the California salmon (Salmo quinnat) have been successfully transported from the United States to nearly all of the European countries. Though the species has always been considered a sea-going salmon, the fry hatched from the eggs sent to the Netherlands have been kept in freshwater ponds, where they have matured and spawned, the young produced from the eggs being as healthy as those hatched in California. These thrive better when confined in freshwater ponds than the native salmon (Salmo salar) under the same conditions, and fish-culturists of that country consider them better suited to their inland waters than any of the native Salmonidæ. It seems probable, from these experiments and from those with other species, that it will be possible to raise any of the Salmonidæ in fresh water.

The exhibits show the fish-cultural apparatus of many countries to be very primitive, and the hatching operations to be limited to a few species of Salmonidæ. The Exhibition cannot fail to advance the interests of fish culture in general, for it will open the eyes of the people to the fact that other species besides salmon and trout are worthy of attention, and can be hatched in enormous quantities without difficulty. Another important result of the Exhibition will doubtl 3 s be to convince the people of the value of fish culture as a means for increasing the food supply. It is indeed fortunate for the future of the science that so deep and widespread an interest has been awa'ened in the subject, for several papers calling in question the results of fish culture have recently made their appearance, and it requires the testimony of the leading authorities to counteract their influence. The testimony is just what might have been expected, and shows that in those countries where the operations have been most extensive confidence is strongest, and in those where work has been limited many question its practicability. Thus in both Sweden and Norway, where only a few thousand fry at most are placed in any stream, many of the hatcheries that formerly existed have ceased to operate, as no immediate results of their work could be seen. The same is true of other localities where the work has been carried on, to a limited extent only, by private parties ; but where extensive hatching operations have been continued through a long period, the beneficial results are invariably acknowledged. Some, who are obliged to acknowledge the value of fish culture in cases where the fry are retained in ponds from which they cannot escape, question its result when the fish are turned out into waters tributary to the sea; these forget that the number of fry turned out by the wash-tub tish-culturists of many countries is so limited when compared with the entire number of fish in a stream, as to have no appreciable effect upon the fisheries. They also forget that, though owing to extensive operations considerable increase in the fisheries of a given locality may be noticeable in three or four years, the full results of artificial propagation cannot be expected until the fry of the artificially-hatche 1 fish have developed into full-grown specimens and returned to the rivers to deposit their eggs. This would require from seven to eight years, as the second generation of any sea-going species can scarcely be expected to return before that period has elapied. Canada and the United States are he only countries where public fish culture has been conducted on a large scale for a sufficient period to warrant a reliable verdict as to the importance of the work; and in both of these countries public opinion is decidedly in favour of continuing the work, and on a larger scale than ever before.

R. EDWARD EARLL

\section{NOTES}

WE regret to learn that M. Dumas has been confined to his bed for the last ten days, although his illness is not in itself serious.

Prof. Cunningham, of the Royal College of Surgeons, Ireland, has just been appointed to the Professorship of Anatomy in the University of Dublin, in succession to Prof. Macalister. The Professorship of Comparative Anatomy, also held by Dr. Macalister, is vacant, but will not be filled up until the meeting of the Academic Council in November or December next.

AN exhibition of electricity and electrical appliances will be held in Philadelphia, United States, commencing on Tuesday, September 2, 1884, under the auspices of the Franklin Institute of the State of Pennsylvania for the Promotion of the Mechanic Arts. From the eminent reputation of this institution, coupled with the fact that the projected exhibition will be the first in America exclusively devoted to this important and progressing branch of science, this announcement has attracted unusual interest throughout the United States, and the exhibition will undoubtedly afford an admirable opportunity of witnessing a representative display of American discovery and invention in electricity. To increase its scientific and industrial importance, as well as to add to its attractiveness, it was determined shortly after its inception to give it an international character. The importance of the project having been properly represented to the Congress of the United Strtes, an Act was passed to this effect, and articles intended for the exhibition will be admitted to the States free of duty. All applications should be made to the Secretary, Franklin Institute, Philadelphia, U.S.A.

The Russian frigate Minineh has just started from the Baltic on a scientific voyage round the world. She has on board a number of Russian savants of every branch of science.

The Prince of Wales is about to try the acclimatisation of the Norwegian ptarmigan at Abergeldie. Of sixty birds taken at Langöen in Nordland, twenty-two have just arrived at Bergen, the rest having died on the wav.

The Electric Railway from Portrush to the Giant's Causeway was opened last Friday by Earl Spencer, and among others present were Sir William Thomson, Sir William Siemens, and Sir Frederick Bramwell. It is over six miles long, and has cost 45,000\% The line, after passing through the principal street of Portrush, follows the seaside road, a portion of a footpath six feet broad being reserved for the railway. The gauge is only three feet, and the gradients are very steep-in places as much as one in thirty-five-and in parts of its course the curves are sharper than might have been desirable had the route which it takes been chosen by the engineers. The force to work it is generated by a waterfall in the River Bush, with an available head of twenty-four feet, the electric current being conveyed by an underground crble to the end of the tramway. The water power passing through turbine water-wheels, which utilise the whole force of the fall, is said to amount to ninety horse.

THE electrical omnibus devised by M. Philippart travelled last Sunday from the Place des Nations to Versailles. The distance is more than 20 kilometres. The experiment was successful, the only incident being a short stoppare occasioned, it appears, by the heating of a coil owing to an excess of current.

Advices from Colombo, under date of August 30, state that on the evening of August 27, at about 5.30, an extraordinary occurrence took place in Colombo Harbour. The sea suddenly subsided about six feet, receding from ten feet to fifteen feet, and owing to the velocity of the outward current the stern moorings of several large vessels gave way. The tide continued to rise and 